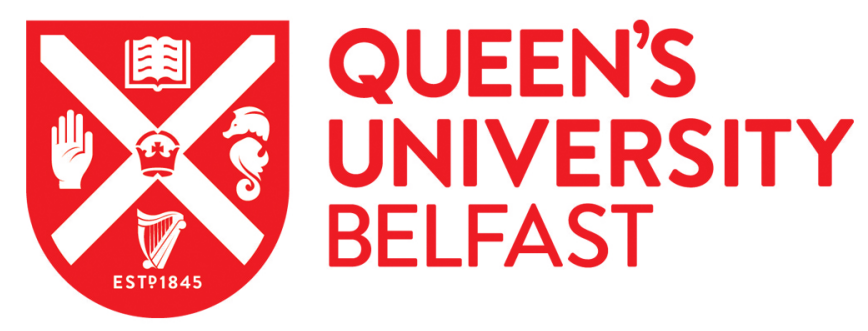

\title{
Development of an aerostatic bearing system for roll-to-roll printed electronics
}

Chen, S., Chen, W., Liu, J., Chen, W., \& Jin, Y. (2018). Development of an aerostatic bearing system for roll-toroll printed electronics. Journal of Micromechanics and Microengineering, 28, [065002]. https://doi.org/10.1088/1361-6439/aab1c9

Published in:

Journal of Micromechanics and Microengineering

Document Version:

Peer reviewed version

Queen's University Belfast - Research Portal:

Link to publication record in Queen's University Belfast Research Portal

Publisher rights

(c) 2018 IOP Publishing Ltd.

This work is made available online in accordance with the publisher's policies. Please refer to any applicable terms of use of the publisher.

\section{General rights}

Copyright for the publications made accessible via the Queen's University Belfast Research Portal is retained by the author(s) and / or other copyright owners and it is a condition of accessing these publications that users recognise and abide by the legal requirements associated with these rights.

Take down policy

The Research Portal is Queen's institutional repository that provides access to Queen's research output. Every effort has been made to ensure that content in the Research Portal does not infringe any person's rights, or applicable UK laws. If you discover content in the Research Portal that you believe breaches copyright or violates any law, please contact openaccess@qub.ac.uk. 


\title{
Development of an aerostatic bearing system for roll- to-roll printed electronics
}

\author{
Shasha Chen ${ }^{1}$, Weihai Chen ${ }^{1}$, Jingmeng Liu ${ }^{1}$,Wenjie Chen $^{2}$ and Yan \\ $\operatorname{Jin}^{3}$ \\ 1 School of Automation Science and Electrical Engineering, Beihang \\ University, Beijing, 100191, China \\ 2 Mechatronics Group, Singapore Institute of Manufacturing Technology, \\ 638075, Singapore \\ ${ }^{3}$ School of Mechanical and Aerospace Engineering, Queen's University Belfast, UK \\ E-mail: whchenbuaa@126.com
}

\begin{abstract}
Roll-to-roll printed electronics (R2RPE) is proved to be an e ective way to fabricate electrical devices on various substrates. High precision overlay alignment plays a key role to create multi-layer electrical devices. Multiple rollers are adopted to support and transport the substrate web. In order to eliminated the negative e ect of the machining error and assembling error of the roller, a whole roll-to-roll system including two aerostatic bearing devices with arrayed restrictors is proposed in this paper. Di erent from the conventional roller, the aerostatic bearing device can create a layer of air Im between the web and the device to realize non-contact support and transport. Based on simpli ed Navier-Stokes equations, the theoretical model of the air Im is established. Moreover, the pressure distribution of the whole ow eld and single restrictor in di erent positions are modeled by conducting numerical simulation with Computational Fluid Dynamics (CFD) software FLUENT. The load capacity curves and sti ness curves are generated to provide guidance for optimizing the sturcture of device. A prototype of the aerostatic bearing system is set up and the experiment tests are carried out. For the proposed aerostatic bearing roller with diameter of $100 \mathrm{~mm}$ and length of $200 \mathrm{~mm}$, the experimental results show the aerostatic bearing method can achieve the position accuracy in a range of $1 \mathrm{~m}$ in the vertical direction of the web, which is much better than that using existing methods.
\end{abstract}

Keywords: Roll-to-roll printed electronics; Micro-positioning ;Aerostatic bearing; CFD simulation; Deviation elimination

\section{Introduction}

Printed electronics has been regarded as a novel technique to create large-scale electrical devices on exible substrates. Moreover, the roll-to-roll process can o er this technology a remarkable solution to manufacture multipurpose, exible and low-price 
electronic devices such as organic thin Im transistor (OTFT), organic light-emitting diodes (OLED), e-paper, exible displays, radio-frequency identi cation devices (RFID), organic photovoltaic (OPV), and so on [1, 2]. Di erent from the conventional printing process which only print a single-layer structure, the printed electronics needs to fabricate electrical devices with di erent materials printed on the same substrate area. Therefore, the alignment accuracy between di erent layers is the critical demand to guarantee the high quality of the electrical devices. In this regard, an high-precision multi-layer alignment system is urgently needed $[3,4,5]$.

In order to exhibition the general R2RPE fabrication process, a schematic diagram of the R2RPE is shown in Fig. 1. The substrate web is released from the unwinding roller, then transported to the pre-processing module for surface treatment. The web tension is detected and adjusted to ensure the web moving smoothly. The web guiding mechanism is generally adopted to adjust the cross-direction position of the web. The printed web will be transported to the post-processing module for drying, heating, cooling, etc, then rolled up by the rewinding roller. The multi-layer printing module is the key module to manufacture multi-layer electronic devices. During the printing process, The multi-layer printed electronics alignment is important to ensure the performance of the electronic devices, which can be regarded as a plane alignment process [6]. The position error of the web in three directions, i.e., machine direction (MD),cross direction $(C D)$ and rotational direction (RD), will cause the misalignment of the printed electronic material in di erent layers. The misalignment is regraded as the most important alignment accuracy index of the R2RPE device, which is called overlay alignment error $[7,8,9]$. The overlay alignment error is generally caused by various factors. The uneven tension of the web will cause extra stretch or wrinkle of the web. Moreover, the machining errors and assembling error of the rollers such as cylindricity error, eccentric error and parallelism error, will cause the dynamic position error of the web. The overlay alignment accuracy of the existing R2RPE technology can realize about 40-100 $\mathrm{m}$ shown in the the current literature, thus the resolution of the printed pattern is restricted to about $100 \mathrm{~m}[10,11]$. For all kinds of high-performance electronic products such as high de nition exible displays which need a print resolution of less than $10 \mathrm{~m}$, existent alignment accuracy is not enough to meet the requirement .

In order to improve the pattern resolution of printed electronic device, many reseachers have conducted various methods to reduce overlay alignment errors. To reduce tension uctuation, a tension adjustment mechanism called Idancer" are widely used to actively or passively compensate the tension deviation [12, 13, 14]. Chargecoupled device (CCD) camera are usually adopted to detect the overlay o set $[8,15]$. A series of control algorithms combined with various actuating mechanism are adopted to compensate the overlay error. A feedforward control strategy is presented to reduce position error from the upstream span based on a theoretical model which combines the MD and CD errors to an oblique MD model $[16,17]$. In order to reduce the overlay alignment error with a decoupling control strategy, a R2RPE equipment is 


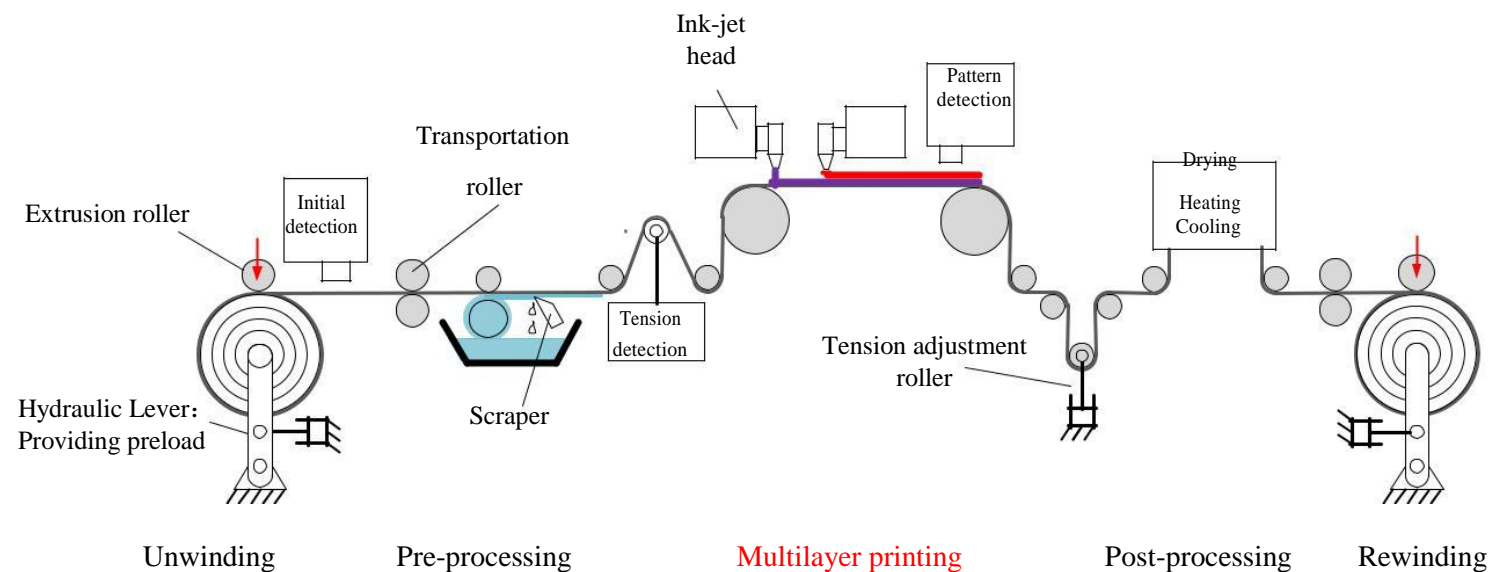

Figure 1. Flow chart of a conventional roll-ti-roll inkjet printing process.

proposed with the rotary actuators and linear actuators eliminating the errors in two direction respectively $[18,19]$. Although the overlay alignment errors can be reduced greatly based on the above method, but the R2R system usually needs to halt and adjust. Thus the work e ciency will be greatly a ected. The compliant mechanism can be adopted to design precision positioning mechanism considering its advantages of eliminated backlash and friction, no need for lubrication, reduced wear and noise, and monolithic con guration [20]. A exure-based XY stage is proposed to compensate the alignment errors for roll-to-roll printed electonics [21]. A R2R multi-layer printing prototype is proposed based on compliant mechanisms [22, 23]. When the position error of the roller is detected, the compliant mechanisms can actively adjust the roller posture to eliminated the error precisely. Moreover, a exure-based roll-to-roll printing system is developed which can achieve sub-nano scale print resolution. The roller posture can be adjusted in real-time [24, 25]. Therefore, the compliant mechanism can be used to improve the error eliminating e ciency and accuracy. However, the dynamic property of the system would be weak since the sti ness of compliant mechanisms in the working direction is relatively low. Overall, the existing techniques adopted to improve the alignment accuracy rarely account the errors casued by the conventional roller. The alignment errors caused by these dynamic position deviation are extremely di cult to be eliminated. Devitt et al. proposed a method to separate the web and the roller by using porous bearings. But they just use it for web support while not consider the transport accuracy of the web [26].

Considering the above facts, the design and study of an aerostatic bearing system with a novel aerostatic bearing module to eliminate the dynamic position error of the web is presented in this paper. A pair of aerostatic bearing devices with arrayed restrictors are adopted to separate the web and the roller. The aerostatic bearing device can generate a thin air Im to prevent contact and friction between the web and the roller. By this mean the machining and assembling errors of the traditional rollers will have not a ect on the web. The reminder of this paper is sturctured as follows: Section 
II presents the prototype description and design consideration of the aerostatic bearing system. In Section III, the theoretical analysis of the air ow eld is established in detail. The CFD simulations for the optimization of the arrayed restictors are shown in Section IV. Moreover, the prototype of whole roll-to-roll system is set up, and experimental tests are carried out to investigate the performance of the aerostatic bearing device in Section V. Finally, the work is concluded and expectation of future works are presented in Section VI.

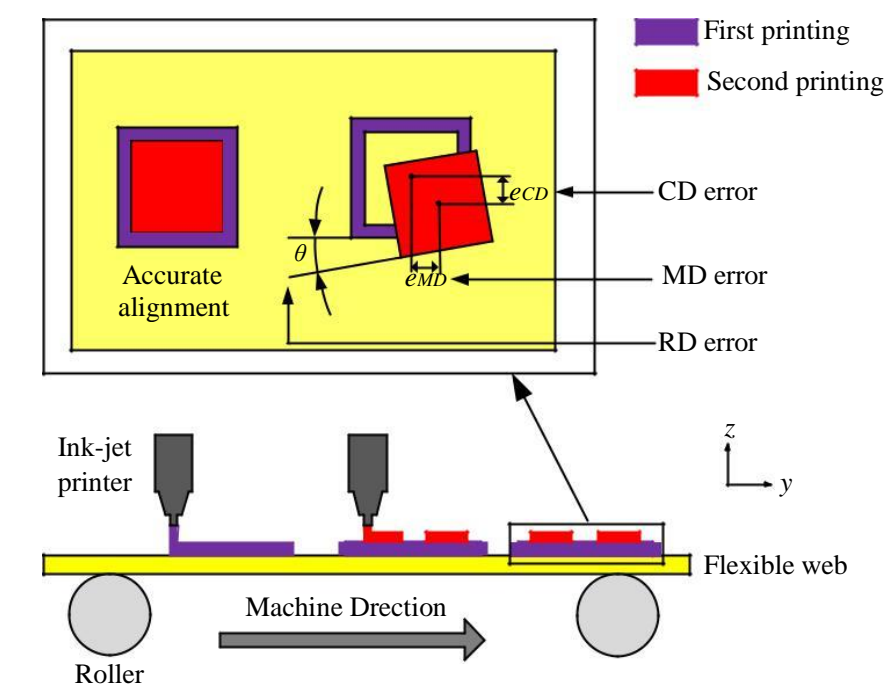

Figure 2. Overlay alignment error model.

\section{System design}

\subsection{Design consideration}

Since the overlay alignment accuracy is the critical limit to the R2RPE system, the overlay alignment error should be eliminated as much as possible. The overlay alignment error model is shown in Fig. 2. The posture deviation of the ink-jet printer, stretching of the web caused by tension variation, machining and assembling errors of the roller have enormous negative e ects on the alignment accuracy. The error caused by the posture of the inkjet printer and the web tension can be eliminated by preset and control strategy optimization respectively. However, the dynamic error caused by the rolling roller is hard to be compensated. As shown in Fig. 3, the machining and assembling errors of the traditional rollers will lead to cylindricity error, eccentric error and parallelism error between di erent rollers. These errors will lead to position uctuation and uneven tension distribution of the web. The uneven tension distribution will cause uneven stretch deformation of the web, which will a ect the position of the ink on the web. All these factors will reduce the accuracy of the multi-layer alignment. However, the dynamic position error caused by the rollers can hardly be eliminated in real-time, which 
will increase the control di culty. Therefore, the key to solve this issue is to design a novel support and transport mechanism which can replace the rolling roller contacting to the web.

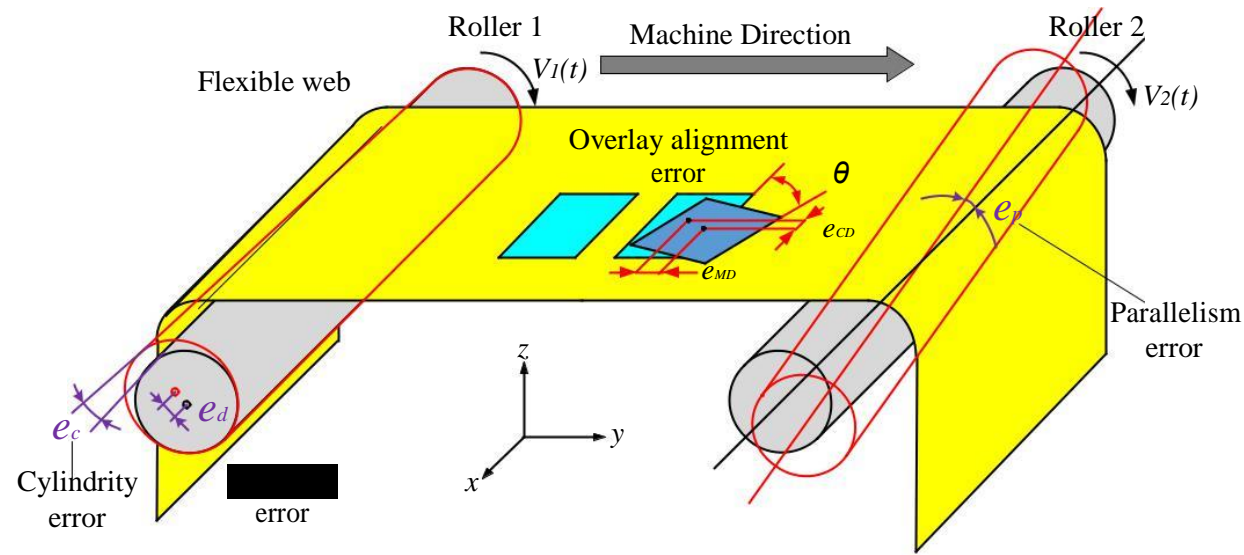

Figure 3. The negative e ects of the conventional rolling roller on overlay alignment accuracy.

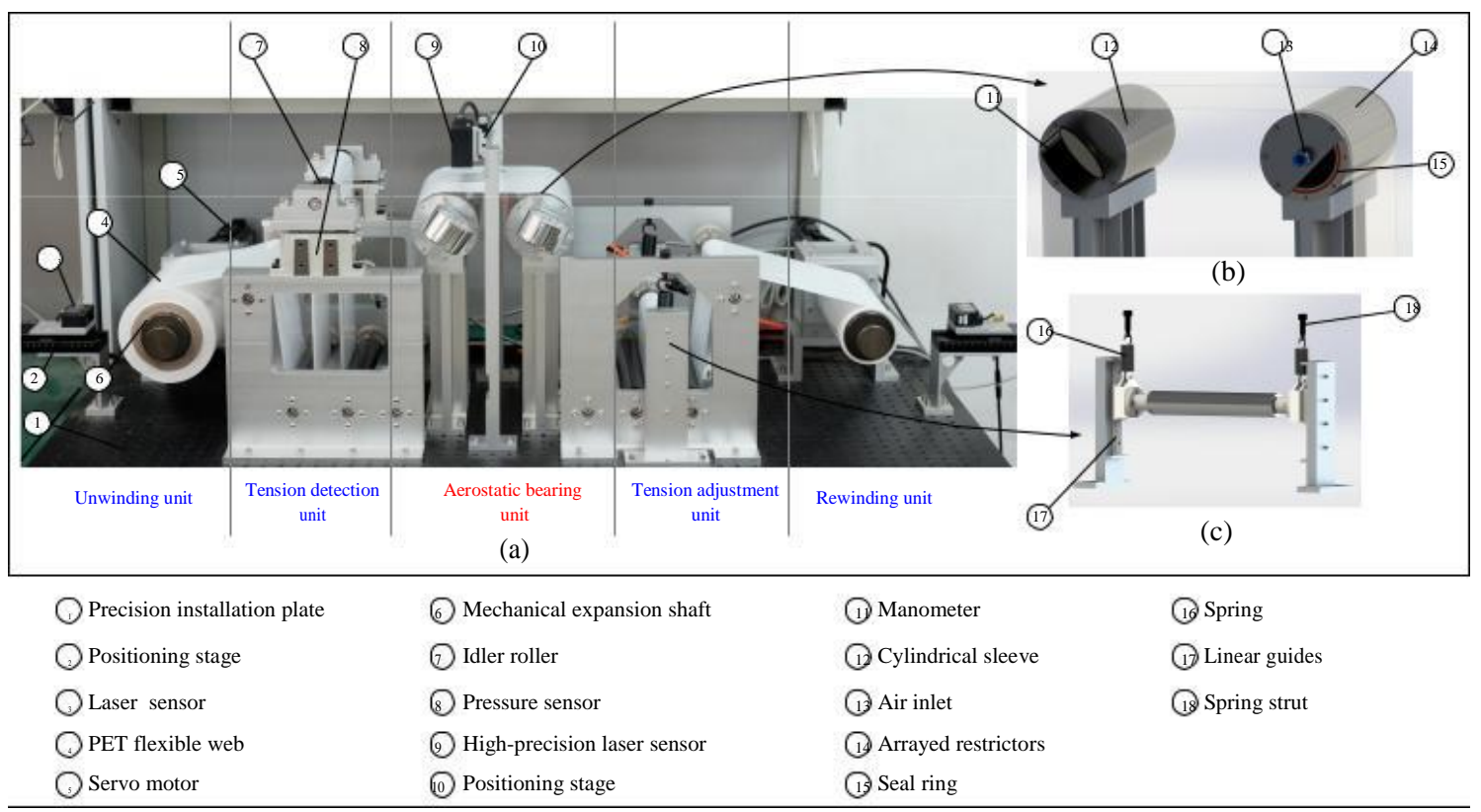

Figure 4. Prototype of the aerostatic bearing system: (a) overall view, (b) static rollers, and (c) passive tension adjustment mechanism.

\subsection{Description of the whole system}

According to the above design considerations, a novel aerostatic bearing system is proposed as shown in Fig. 4. It can be seen that the whole system assembled on a precision installation plate consists of ve modules, i.e., the unwinding module, 
the tension detection module, the aerostatic bearing module, the tension adjustment module, and the rewinding module.

The aerostatic bearing module is the core part of the system which contains a pair of static rollers. As shown in Fig. 4(b), the static roller mainly includes a cylindrical sleeve with arrayed restrictors on the surface, two side covers, an air inlet, and a high accuracy manometer to detect the air pressure. A high-precision laser sensor (LK-H020, KEYENCE) with $6 \mathrm{~mm}$ measurement range and $20 \mathrm{~nm}$ resolution is adopted to detect the oat height and the vibration performance of the web. Through the duration of the external air supply, the cavity of the roller is lled with compressed air, an air Im will be formed by the arrayed restrictors between the substrate web and the static roller. The web and the static roller is separated from each other by the generated air $\mathrm{Im}$, thus no contact and friction would exist between the two surfaces. By the method, the position of the web will not be a ected by the adverse factors of the conventional rolling rollers.

The unwinding module consists of a mechanical expansion shaft driven by a servo motor (ECMA-C10604SS, DELTA). The diameter of the shaft can be adjusted by the handle to install or uninstall the web reel. The diameter of the web reel changes along with the web transport. In order to maintain constant velocity and tension of web, the velocity and torque of the serve moto should be varied. A laser sensor (IL-S065, KEYENCE) is adopted to detect the diameter variation of the web reel for velocity and torque control of the servo motor. The rewinding module is assembled like the unwinding module.

The tension detection module and the tension adjustment module are formed to control the web tension. In the tension detection module an idler roller is assembled on two tension detectors (LX-030TD, MITSUBISHI). The load on the tension detector will be recorded to calculate the web tension. The obtained tension will be used for the servo control feedback and load capacity calculation of the aerostatic bearing roller. As shown in Fig. 4(c), a passive tension adjustment mechanism is adopted in the tension adjustment module. The ends of an idler roller are assembled on two linear guides with slider connected to a spring. This tension adjustment mechanism will provide preload tension and neutralize tension uctuations passively. The other series of idler rollers are assembled on the mounting plates.

\subsection{Selection of the restrictor}

$\mathrm{Di}$ erent structures of the restrictors have di erent e ects on the performance the aerostatic bearing device [27, 28]. Generally the restrictors have di erent structures of narrow channels which is used for stabilizing air pressure to obtain di erent load capacity and sti ness of the air $\mathrm{Im}$. Two of the most common restrictors, i.e., the inherent ori ce restrictor and the simple ori ce restrictor, are shown in Fig, 5. It can be seen that the di erence between the two structure is the throttling area, which means the minimum cross section of the air ow channel. As shown in Fig 5(a), the throttling 


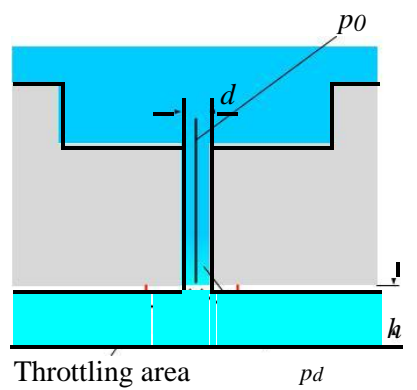

(a)

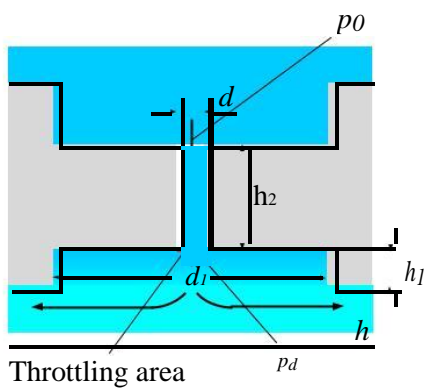

(b)

Figure 5. Structure of two ori ce restrictors: (a) inherent ori ce restrictor and (b) simple ori ce restrictor. ( $p_{0}$ : pressure at the ori ce inlet, $p_{d}$ : pressure at the ori ce outlet, d: diameter of the ori ce, $\mathrm{d}_{1}$ : diameter of the air cavity, $\mathrm{h}$ : thickness of the air Im, h1: height of the air cavity, h2: length of the or ce.)

area of the inherent ori ce restrictor refers to an annular surface at the outlet of the ori ce. The air Im thickness $\mathrm{h}$ is the height of the annular surface. If the air Im thickness changes, the throttling area of the inherent ori ce will change at the same time. Thus the the load capacity and sti ness of the air Im will be unstable. It can be seen that the throttling area of the simple ori ce restrictor is the cross section of the ori ce as shown in Fig 5(b). The load capacity and sti ness of the air Im stay stable since the throttling area will not change along with the air Im thickness. In order to keep the simple ori ce characteristic, the ori ce cross section should be guaranteed as the minimum area of the air channel. To this end, an air cavity need to be constructed at the outlet of the ori ce. The parameters of the restrictor need to meet the following requirements

$$
\begin{aligned}
& d_{1} h>\frac{d^{2}}{4} ; \\
& d\left(h_{1}+h\right)>\frac{d^{2}}{4} ;
\end{aligned}
$$

where $d_{1}$ and $h_{1}$ are the diameter and the height of the air cavity and $d$ is the diameter of the ori ce. (1) and (2) can be written as

$$
\begin{gathered}
d_{1}>\frac{d_{2}}{4 h} ; \\
h_{1}>\frac{d}{4} \quad h:
\end{gathered}
$$

Overall, the simple ori ce restrictor can be obtain under the satis ed conditions (3) and (4). 


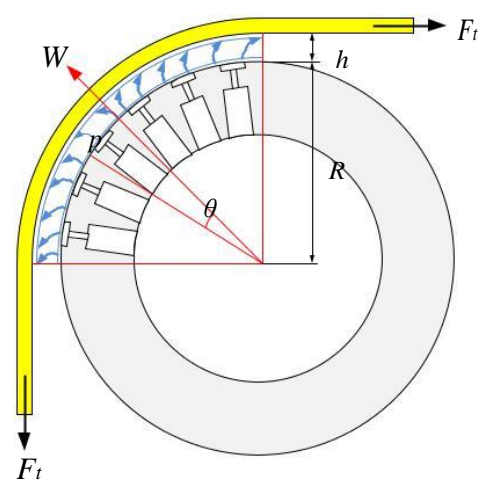

Figure 6 . Working principle of the aerostatic bearing device

\section{Modeling and analysis}

\subsection{Load capacity consideration}

The load capacity is a key factor to the performance of the aerostatic bearing device. In order to support the web, the relationship between the web tension and the load capacity should be analysed. Fig. 6 shows the working principle of the aerostatic bearing device. It can be seen that an air Im is generated to separate the static roller and the web. The load capacity of the air $\mathrm{Im} \mathrm{W}$ can be derived as follow

$$
\mathrm{W}=2_{0}^{Z_{0}}{ }_{0}^{Z_{L_{4}}} \operatorname{prcos} d x d ;
$$

where $p$ is the pressure at the surface of exible web; $r$ is equal to the sum of $R$ and $h ; R$ is the radius of the cylindrical sleeve and $h$ is the thickness of the generated air $\mathrm{Im}$; $\mathrm{L}$ is the length of the air ow eld in cross direction.

Since the exible web has a thin thickness and low density, the weight of the web can be negligible. According to the force balance analysis, the relationship between the load capacity and the web tension $\mathrm{F}_{\mathrm{t}}$ can be given as follow $p$

$$
\mathrm{W} 2 \mathrm{~F}_{\mathrm{t}}=0 \text { : }
$$

Considering (5) and (6), the relationship between the web tension and the air pressure can be derived as

$$
F_{t}=P_{2(R+h)} Z_{0} Z_{0}{ }^{L} p \cos d x d:
$$

3.2. Mathematical model of the air ow eld

The law of conservation of mass in the aerostatic lubrication can be described as: the increased mass of the gas control micro unit equals the net mass of the uid owing into the micro unit in the same time [29]. Based on the continuity equation, it can be derived as 


$$
\frac{@(u)}{@ x}+\frac{@(v)}{@ y}+\frac{@(w)}{@ z}=\frac{@}{@ t} \text {; }
$$

where is the density of the micro unit, $t$ is the time and $u, v, w$ are the velocities in three directions.

The compressed air provided by the external gas source ows into the air Im clearance through the restrictors, and then ows out through the boundary of the web. The entire process can be regarded as isothermal and defrived by the state equation as

$$
\underline{p}=\underline{p_{a}}
$$

where $\mathrm{p}_{\mathrm{a}}$ and $\mathrm{a}$ are the pressure and density of the atmosphere.

The pressure distribution of the air ow eld can be derived by adopting the NavierStokes equations. The Navier-Stokes equations are a series of equations to explain the the basic ow laws of the viscous uid which can be given as follows [30, 31].

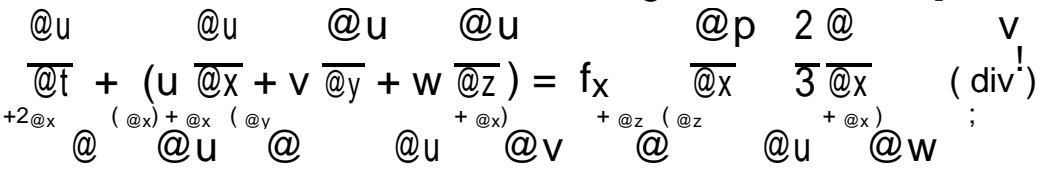

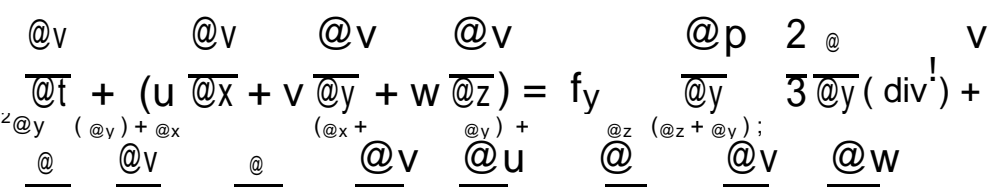

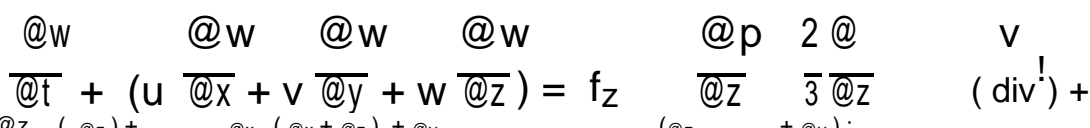

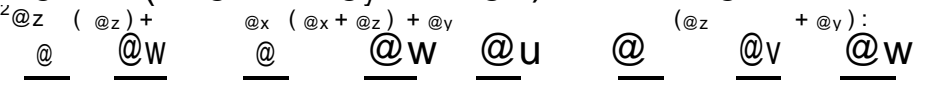

In order to simpli ed the Navier-Stokes equations, they can be transferred to dimensionless equations and the dimensionless items can be given as $\mathrm{u}=\mathrm{V} \mathrm{u}$; $\mathrm{v}=$ $\left(\mathrm{l}=\mathrm{h}_{\mathrm{m}}\right) \mathrm{v}=\mathrm{V} \mathrm{v} \overline{;} \mathrm{w}=\mathrm{V} \mathrm{w} x=\mathrm{I} ; \mathrm{y} \equiv \mathrm{h}_{\mathrm{m} y} ; \mathrm{z}=\overline{\mathrm{y}}=\mathrm{bz} ;\left(\mathrm{b}=\mathrm{I}==^{-} \quad\right.$ ), where $\mathrm{V}$ is the characteristic velocity, $h_{m}$ is the reference quantity of the air $I m, I$ and $b$ is the characteristic length of the roller in the $x$ and $z$ direction. Moreover,

$$
-=\frac{\mathrm{m}}{\mathrm{p}} \overline{\mathrm{p}}=\underset{\mathrm{p}_{0}}{\mathrm{p}} ; \overline{\mathrm{t}}=
$$
$\frac{t}{l=V} \quad ;=\frac{h_{m}}{I}$. The Reynolds number is given as $R e=\frac{V h m}{m} . m$, where $p_{0}, I=V$ are the the characteristic quantities of viscosity coe cient, air pressure and time, respectively. Based on above relationships, the Navier-Stokes equation can be derived as

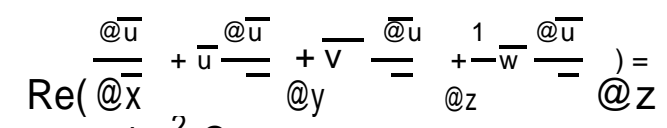

$$
\begin{aligned}
& \text { pohm_@p 2@_ } 2 \text { - } 2 \overline{\mathrm{v}}
\end{aligned}
$$

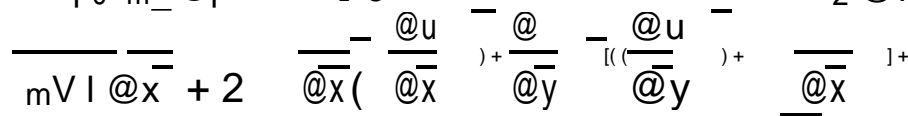

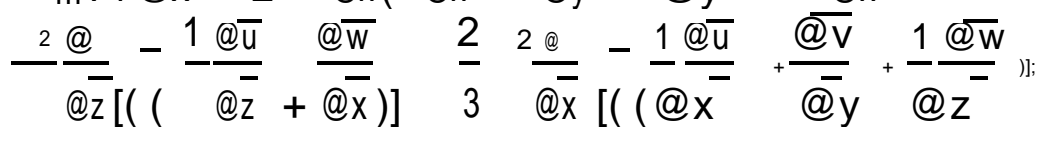




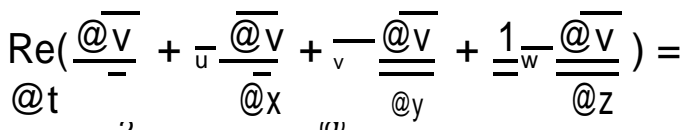

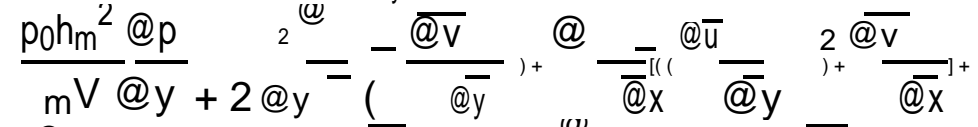

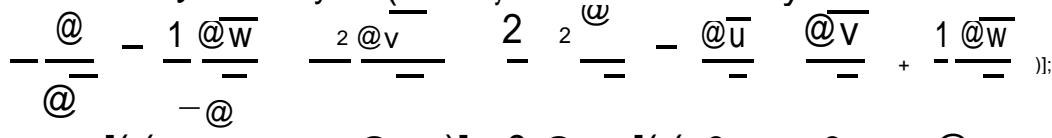

$$
\begin{aligned}
& \text { z [( ( y + @z )] 3@y [( ( @x + @y @z } \\
& \frac{@ \overline{\mathrm{w}}}{-}-\frac{@ \overline{\mathrm{w}}}{\varrho^{-}}-\frac{@ \overline{\mathrm{w}}}{\varrho^{-}}+\frac{1}{-}-\frac{\varrho \overline{\mathrm{w}}}{-} \\
& \operatorname{Re}(@ \mathrm{t} \quad \mathrm{ux}+\mathrm{v} y \quad \mathrm{w} @ \mathrm{z})=
\end{aligned}
$$

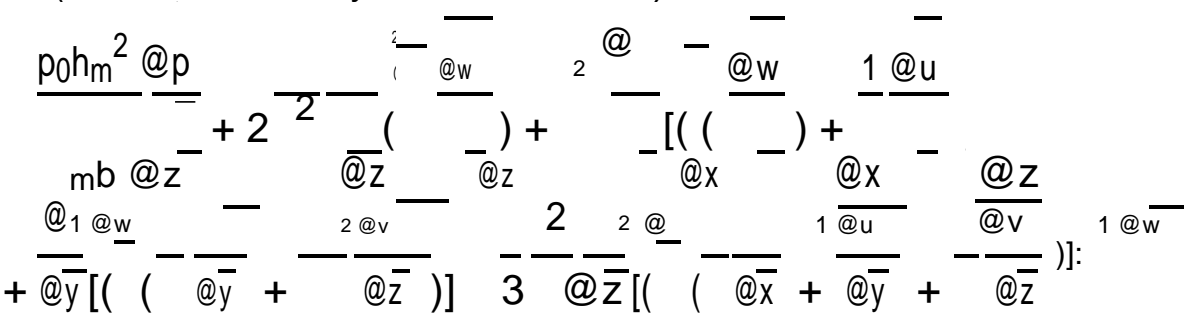

Considering that the thickness of the air $\mathrm{Im} h$ is much lower than the roller's characteristic length I which can be de ned by the width of the web $L$ or the radius of the roller $\mathrm{R}$. In most cases, $\mathrm{h}=\mathrm{I} 10^{4} 10^{3}$. Based on this consideration, any item that contains , ${ }^{2}, R e,{ }^{2} R e$ is relatively small dimensionless item, which can be omitted. Therefore, the inertia term in the Navier-Stokes equations can be removed. Considering above facts, the simpli ed Navier-Stokes equations can be derived as

$$
\begin{aligned}
& \frac{@ p}{@ x}=\frac{@}{@ y}\left(\frac{@ u}{@ y}\right) ; \\
& \frac{@ p}{@ y}=0 ; \\
& \frac{@ p}{@ z}=\frac{@}{@ y}\left(\frac{@ w}{@ y}\right) ;
\end{aligned}
$$

where is the viscosity coe cient of air and the velocity boundary conditions of the air ow eld can be given as $u=u_{1}, v=0, w=w_{1}$, when $y=0 ; u=0, v=0, w=0$, when $y=h$. Integrating (18)-(20) twice with respect to $y$, the velocity distribution can be derived as

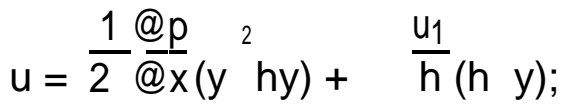

$$
\begin{aligned}
& w=\underline{1} @ \underline{p}\left(y_{2} \text { hy }\right)+\underline{w_{1}}\left(\begin{array}{ll}
h & y
\end{array}\right):
\end{aligned}
$$


$2 @ z$

h

Integrating (8) with respect to $\mathrm{y}$, leads to

$@(@ \mathrm{t})+@ x\left(<_{0} \mathrm{~h}\right.$

$\underline{\mathrm{h}} \stackrel{@}{\varrho}$ 
Substituting (9) (21) (22) into (23) and solving the integral, the motion equation of the air ow eld is derived as

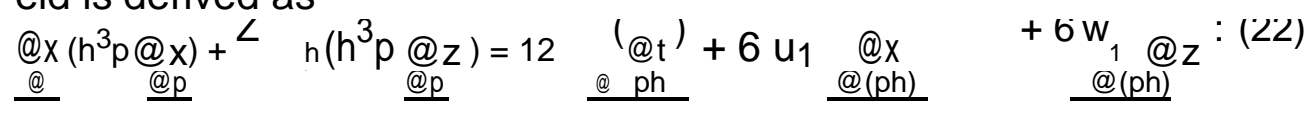

Discretizing the equations (16) (17) (18) (22) based on nite volume method, the generated characteristic equations can be calculated to solve uid ow problems by numerical calculation software in computer.[32, 33].

\section{CFD simulations of the air ow eld}

In order to establish the numerical model of the ow eld to study the property of the air Im, the computer uid dynamics (CFD) simulation is conducted. By de ning the property of the uids and the various boundary conditions, the numerical calculation is performed by high-performance computer. For the sake of obtaining the air pressure distribution of the air ow eld to calculate the load capacity and sti ness, the commercial CFD software FLUENT is 14.5 adopted. Gambit 2.4.6 is adopted as the pre-processor to construct and mesh the 3D structure of the air ow eld. The air Im is expanded and modeled as shown in Fig.7. Fig. 7(a) shows the mesh model of the air ow eld and Fig .7(b) explains its boundary condition settings. A $\mathrm{m} n$ restrictor array is uniformly distributed in the air ow eld, where $m$ denotes the quantity of the restrictors in cross direction, and $\mathrm{n}$ denotes the quantity of the restrictors in machine direction respectively. The structure parameters of aerostatic bearing device are illustrated in Table I. The material of the substrate web is selected as polyethylene terephthalate (PET) plastic with its property given in Table II. In order to optimize the structure of the aerostatic bearing device, the quantity of the restrictor and the diameter of the ori ce are varied based on the simulation results.

Table 1. Parameters of the Aerostatic Bearing Device

\begin{tabular}{ll}
\hline Parameters & Value \\
\hline Radius of the cylindrical sleeve $(\mathrm{R})$ & $50 \mathrm{~mm}$ \\
Width of the exible web $(\mathrm{L})$ & $200 \mathrm{~mm}$ \\
Diameter of the air cavity $\left(\mathrm{d}_{1}\right)$ & $3 \mathrm{~mm}$ \\
Height of the air cavity $\left(\mathrm{h}_{1}\right)$ & $0.16 \mathrm{~mm}$ \\
Depth of the ori ce $\left(\mathrm{h}_{2}\right)$ & $1 \mathrm{~mm}$ \\
Number of restrictors in axial direction $(\mathrm{m})$ & 20 \\
Air supply pressure $\left(\mathrm{p}_{0}\right)$ & $0.025 \mathrm{Mpa}$ \\
\hline
\end{tabular}

\subsection{Structure modeling of the air ow eld}

According to the symmetry of the air ow eld, the mesh model of only a quarter of the air ow eld is constructed to reduce amount of calculation as shown in Fig. 7(a). Fig. 


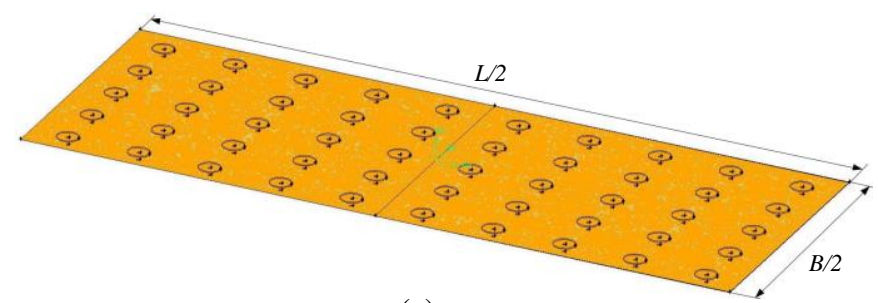

(a)

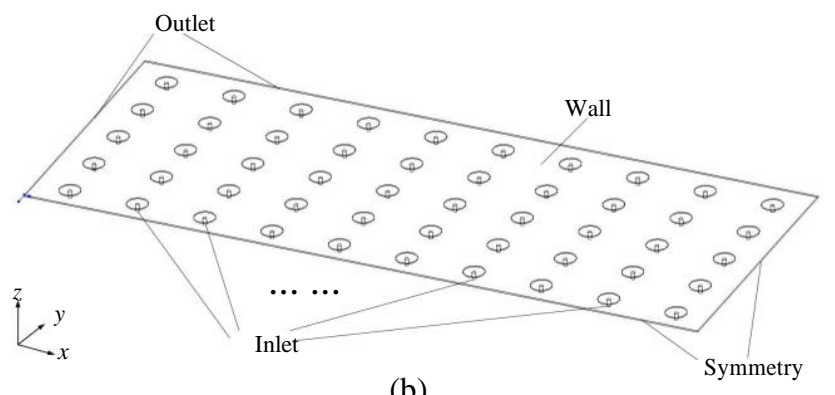

(b)

Figure 7. 3D model of the expended ow eld: (a) mesh model and (b) boundary conditions.

Table 2. Material Properties of the PET Web

\begin{tabular}{ll}
\hline Properties & Value \\
\hline Density ( ) & $1.42 \mathrm{~g} / \mathrm{mm}^{3}$ \\
Young's modulus (E) & $2.96 \mathrm{Gpa}$ \\
Tensile strength ( b) & $57.3 \mathrm{Mpa}$ \\
Poisson ratio (v) & 0.37 \\
Thickness & $50 \mathrm{~m}$ \\
\hline
\end{tabular}

7(b) shows the boundary conditions for the CFD analysis. Generally, the higher mesh density divided, the more accurate the results obtained. Therefore, the mesh should be divided as dense as possible. However, the geometric size of the ow eld spans large. The length and width of the ow eld are as large as tens of millimeters, while the thickness of the air Im is as small as several microns. Thus, it is di cult to divided a dense mesh. If the mesh is too loose, the CFD simulation would not get convergent solution due to iteration error. The CFD simulation in this article selects di erent kinds of meshes based on the size of the ow eld in di erent directions. Moreover, the mesh at the ori ces boundary is more dense. Based on these methods, the CFD simulations can get accurate convergent solution as much as possible. Moreover, it can be seen that the curvature of the air Im is ignored, the ow eld is spreaded as a plane with the same height to generate high quality mesh structure.

The width of the air ow eld $B$ is given as

$$
B=\frac{R}{2} \text { : }
$$

In order to simplify the load capacity calculation, the air ow eld can be divided into $n$ areas according to the row quantity of the restrictors in the machine direction. 
It can be concluded that the pressure distribution in vertical direction of the air ow eld is invariable according to (10)-(12). According to the above conclusion, the load capacity of the i-th area can be derived as

Z

$$
F_{i}=2 \int_{0}^{\overline{4 n}} \quad p_{i} L(R+h) \cos d ;
$$

where $\mathrm{p}_{\mathrm{i}}$ is the average pressure of the $\mathrm{i}$-th area. The load capacity of the entire air ow eld can be calculated as

$$
W=2 \sin \overline{4 n} \quad \begin{gathered}
X_{i} \\
L(R+h) \quad p i \cos i: \\
=1
\end{gathered}
$$

The static sti ness $\mathrm{KW}$ of the air ow eld can be given as

$$
K_{w}=\frac{W(h+h) W(h)}{h} \text {; }
$$

where $\mathrm{h}$ represents the change of the air Im thickness.

\subsection{Structure optimization of the arrayed restrictors}

Di erent from the conventional aerostatic bearings which are regarded as rigid body, the PET web is exible. If the exible web cannot be supported by uniform pressure, the boundary conditions of the ow eld will be unstable. Therefore the uniform pressure of the air ow eld needs to be guaranteed. A CFD model of the ow eld is generated and the pressure nephogram is shown in Fig. 8(a), where the air Im height is $40 \mathrm{~m}$, the number of the restrictor is 2010 and the diameter of the ori ce is $0.3 \mathrm{~mm}$. It can be seen that an obvious pressure drop appears at the edge of the air ow eld. This pressure drop will decrease the stability of the boundary condition. In order to increase the air pressure at the edge, a round of additional restrictors are added. The pressure nephogram of the air ow eld with the additional restrictors are shown in Fig. 8(b). It can be seen that the pressure drop at the border is signi cantly reduced compared with the pressure distribution in Fig. 8(a), forming the uniformity of the air ow eld. As shown in gure. 9, the pressure distribution of the curve center section of the air $\mathrm{Im}$ are given. Line-test1 represents the center section pressure distribution of the ow eld without additional restrictors while line-test2 represents the pressure distribution of the center section of the ow eld with additional restrictors. The increase of the pressure at the edge can be recognized with the additional restrictors.

Moreover, the CFD simulations of the single ori ce near the boundary and in the center of the ow eld are conducted, respectively. As shown in Fig. 10, the pressure nephograms of each condition are illustrated. The pressure at the inlet is set as $0.25 \mathrm{Mpa}$, the diameter of the ori ce is $0.3 \mathrm{~mm}$ and the thickness of the air $\mathrm{Im}$ is $40 \mathrm{~m}$. Moreover, since the thickness of the air Im is small compared with the size of the ow eld, the distribution of the grid in the Im thickness direction is denser. The viscous model is selected as realizable kepsilon, the energy equation is on, and the uid material is selected as air with ideal-gas density. The pressure-velocity coupling scheme is chosen as simple. The spatial discretization is set as follows: least squares cell based gradient, 
standard pressure, second order upwind density and momentum, and rst order wind turbulent kinetic energy. According to the CFD simulations, it can be observed that the pressure distribution of the ori ce in the center is more uniform than the pressure distribution of the ori ce near the boundary. Therefore, the addition of a round of restrictors is necessary. Moreover, Fig. 10(c) shows the velocity vector of the air ow near the outlet of the ori ce. Turbulence occurs at the outlet of the ori ce, as well as the intersection of each ori ce in the arrayed restrictors ow eld. Therefore, it is di cult to calculate the pressure distribution of the ow eld analytically. Nevertheless, we can study the property of the whole ow eld by conduct CFD simulation of the whole air Im to calculate the load capacity and sti ness of the aerostatic bearing device to the web.

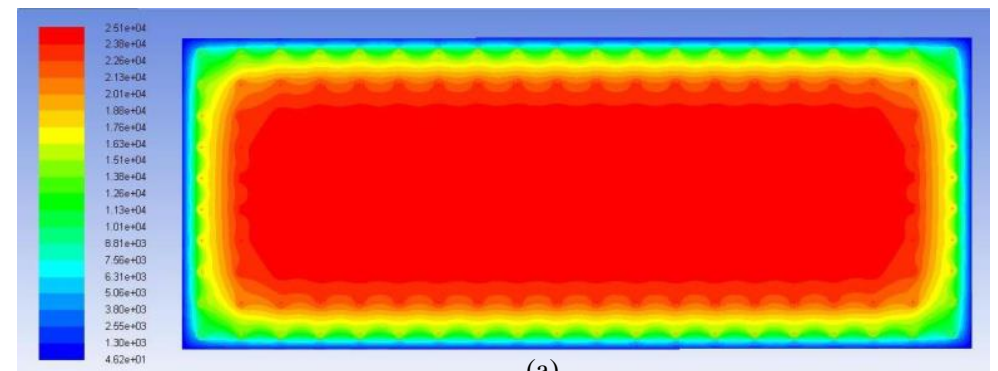

(a)

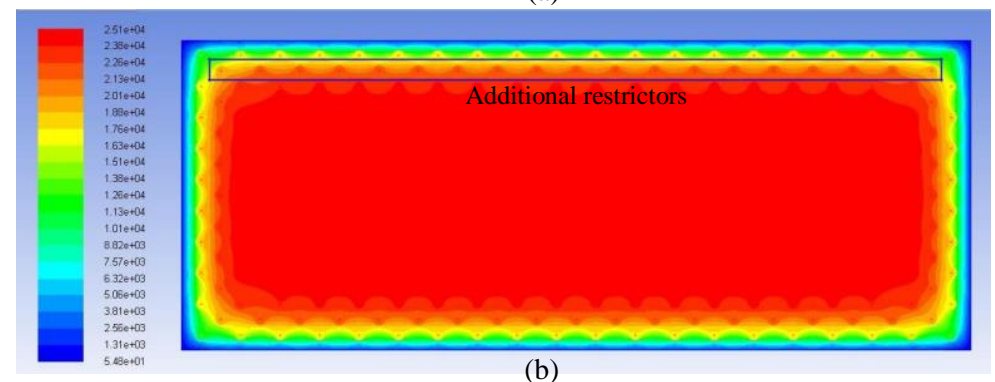

Figure 8. Pressure nephogram of the ow eld : (a) without additional restrictors and (b) with additional restrictors.

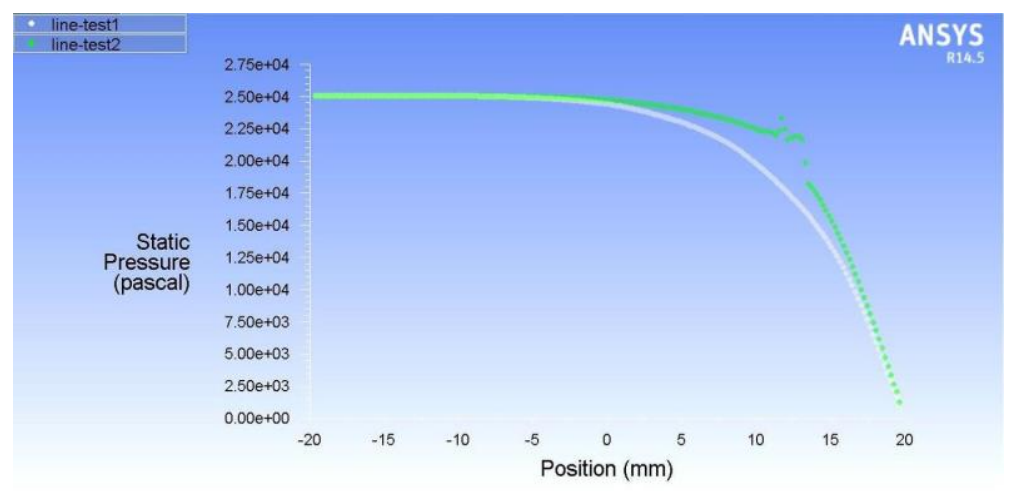

Figure 9. Center section pressure distribution curve. 


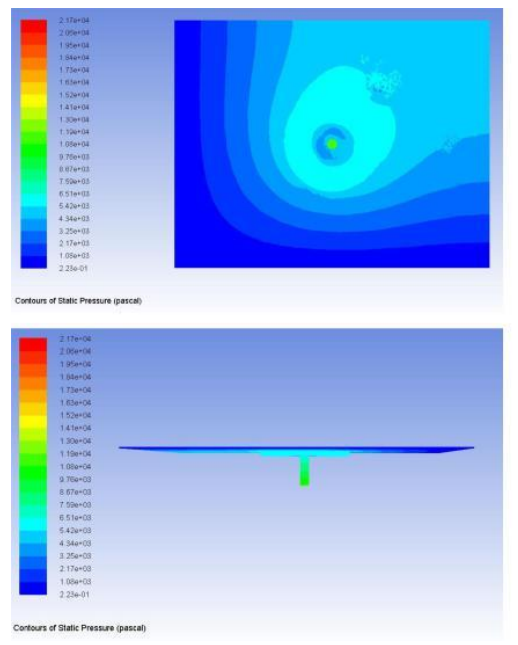

(a)

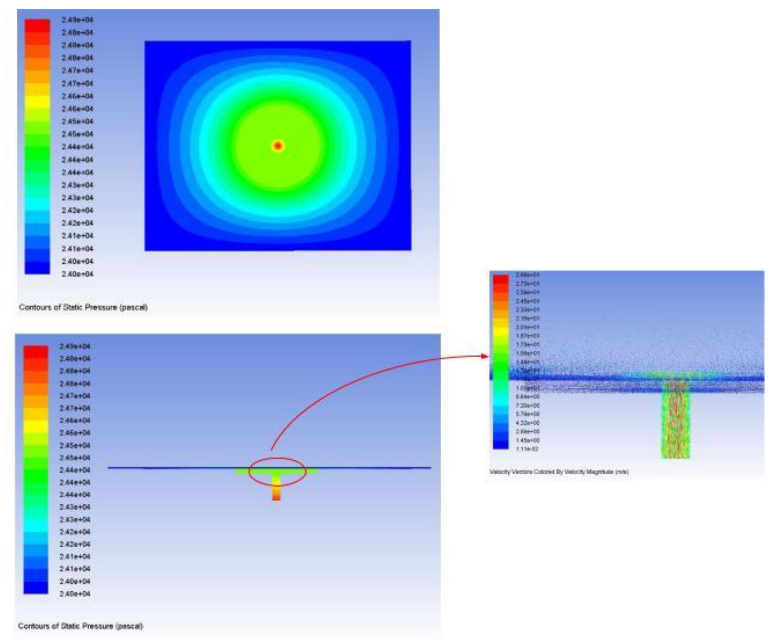

(b) (c)

Figure 10. (a) Pressure nephogram of a single ori ce at the corner of the ow eld,

(b) pressure nephogram of a single ori ce at the center of the ow eld and (c) velocity vector of the air ow near the outlet of the ori ce.

\subsection{CFD simulation of load capacity and sti ness}

The aerostatic bearing device is mainly evaluated by its load capacity and sti ness. In order to optimize the performance of the aerostatic bearing device, research should be done to study the in uence of aerostatic bearing device structure parameters. Based on simple variable method, the structure parameters are varied to conduct repeated CFD simulation about the load capacity and sti ness of the air ow eld. Finally, the variation curves of the load capacity and sti ness with respect to the thickness of the air Im are plotted. Fig. 11 shows the curves when the quantity of the restrictor rows is set to 10 and the diameter of the ori ce is varied, while Fig. 12 shows the curves when the diameter of the ori ce is $0.3 \mathrm{~mm}$ and the number of the restrictor rows is varied.

According to the CFD simulation results the following conclusions can be given.

When the diameter of the ori ce is increased, the load capacity of the aerostatic bearing device is higher. It is mainly resulted from the increase of the air pressure at the outlet of the ori ce. However, the maximum sti ness of the ow eld is signi cantly decreased. Therefore it can be concluded that smaller diameter of the ori ce resulting in lower load capacity and higher sti ness. However, processing di culty will be greatly increased when the diameter of the ori ce is too small. Meanwhile the cleanliness of the air source will be tougher to prevent the impurities in air from blocking the restrictor.

When the number of the restictors is increased, the load capacity of the air ow eld is higher while the maximum sti ness is lower. However, once the the number of the restictors is up to a su cient extent, it has little e ect on the load capacity 
and sti ness of the air ow eld as shown in Fig. 11. Therefore, if the uniformity of air ow eld can be ensured, the number of the restrictors should be restricted since larger quantity of restrictors leads to higher manufacturing di culty and greater expense.

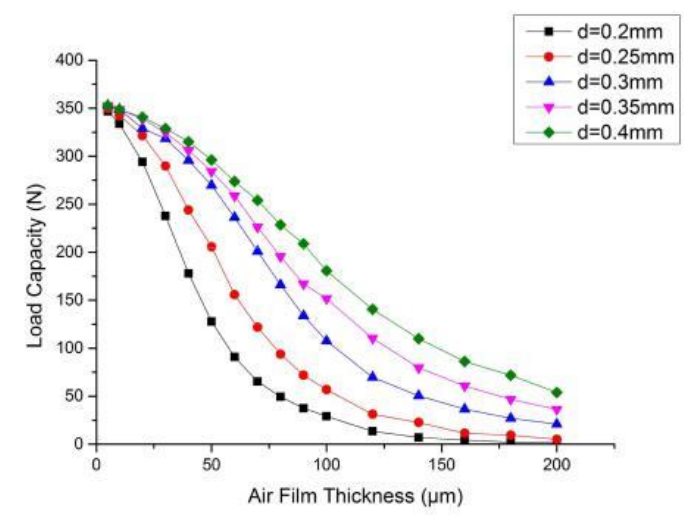

(a)

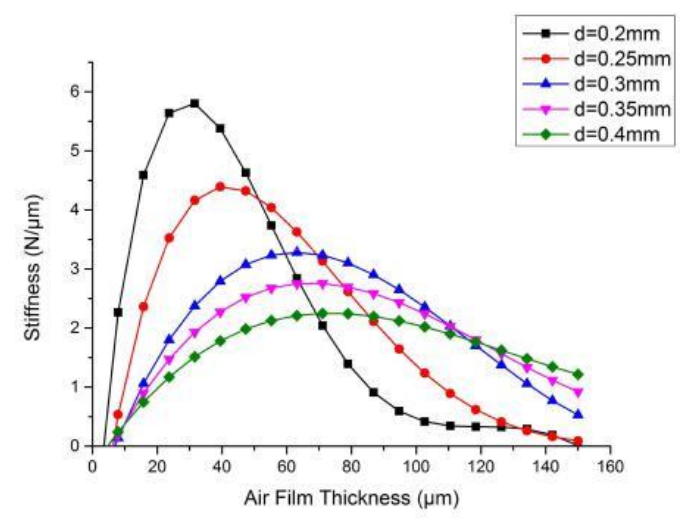

(b)

Figure 11. A ection of the diameter of the ori ces on (a) load capacity and (b) sti ness.

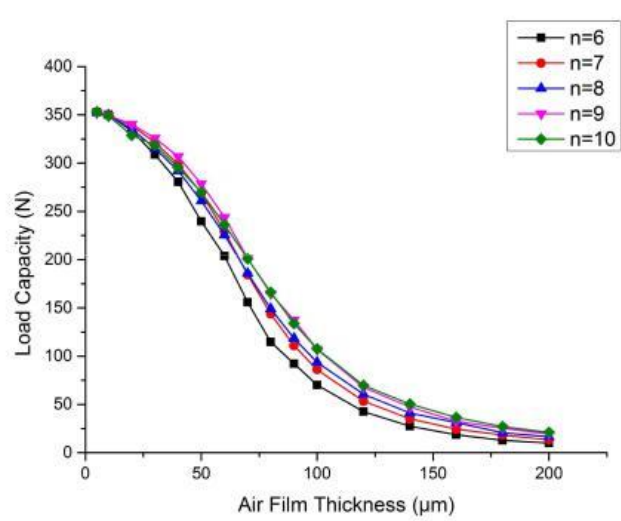

(a)

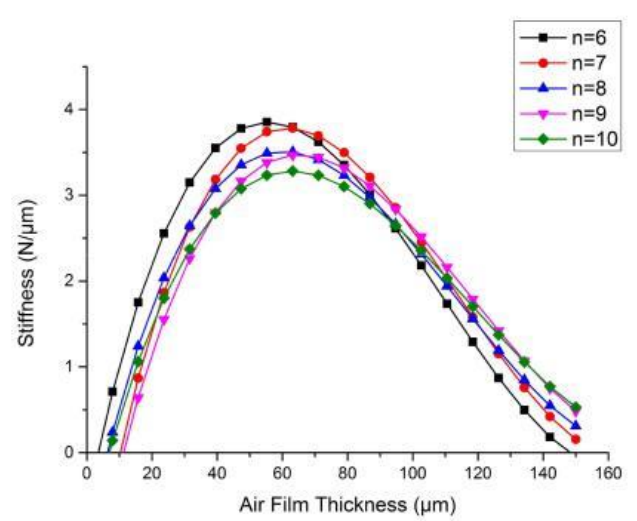

(b)

Figure 12. A ection of the quantity of the restrictor rows on (a) load capacity and (b) sti ness.

\section{Experimental tests}

Experimental tests are carried out to investigate the performance of the aerostatic bearing system. A 2010 restrictor array at $0.2 \mathrm{~mm}$ diameter is distributed on the surface of the aerostatic bearing device. The left parameters of the device is the same as used in the CFD simulation shown in Table I. 


\subsection{Tension control strategy}

The web tension should be kept at a constant in the printing process. Inappropriate tension will in uence the transport stability and the printing quality. The web would be deformed or ruptured if the tension is too high. While a slide or wrinkles would appear if the tension is too low.

Figure.13 shows the schematic diagram of the tension control system. Servo motor 1 works at the torque model while servo motor 2 works at the velocity model to set the tension and velocity of the web, respectively. In order to keep the web tension and velocity constant, the resistance torque and rotating speed of the servo motors should change along the variation of the web reel diameter. Two laser sensors are employed to measure the diameter. The tension detector will detect the load on the idler roller generated by the web tension. When the actual tension deviates from the predetermined value, the resistance torque of servo motor 1 should be revised through speci c control algorithms. Besides, the spring tension adjustment mechanism is used to compensate the tension uctuation passively.

As shown in Fig.14, the tension variation is detected by the pressure sensor. The web velocity is set at $30 \mathrm{~mm} / \mathrm{s}$. The tension uctuation is controlled within $1 \mathrm{~N}$.

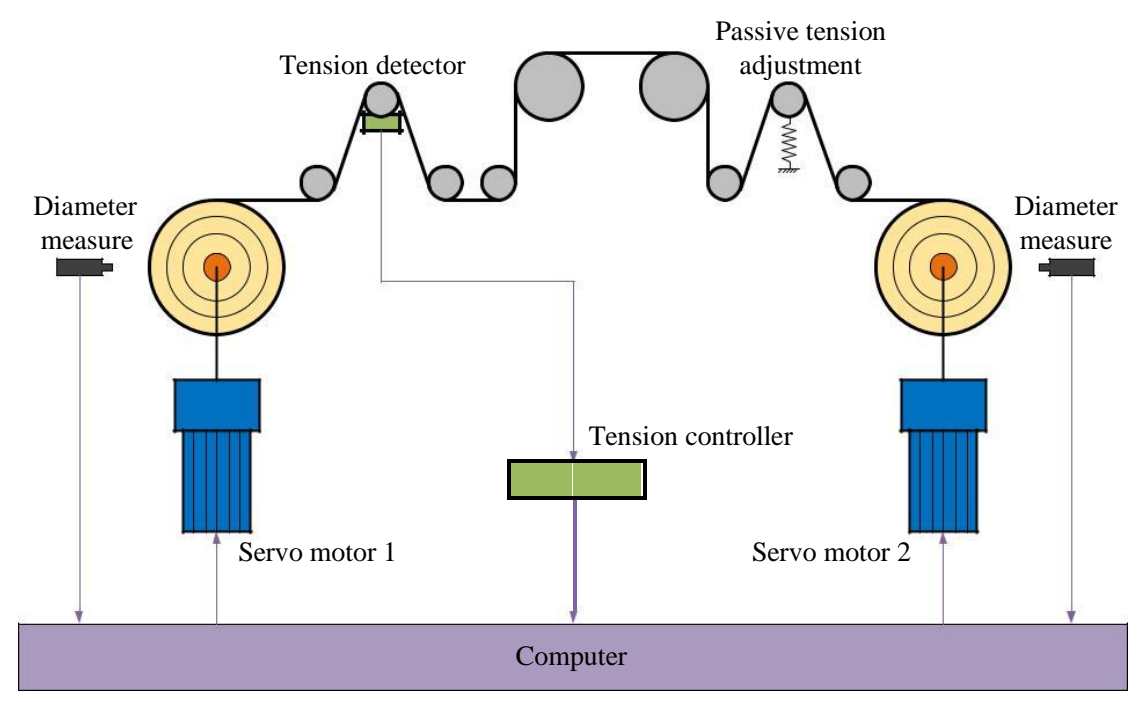

Figure 13. Schematic of the tension control system.

\subsection{Performance test of the aerostatic bearing system}

Experimental tests are carried out to investigate the performance of the aerostatic bearing system. A high precision laser sensor is adopted to detect the oat height and vibration performance of the web. The environmental noise of the laser sensor is measured as shown in Fig. 15, and it can be seen that the noise is about $0.1 \mathrm{~m}$.

Once the variation of the air $\mathrm{Im}$ thickness along the web tension is obtained, the load capacity and the sti ness of the air Im can be calculated. The comparison 


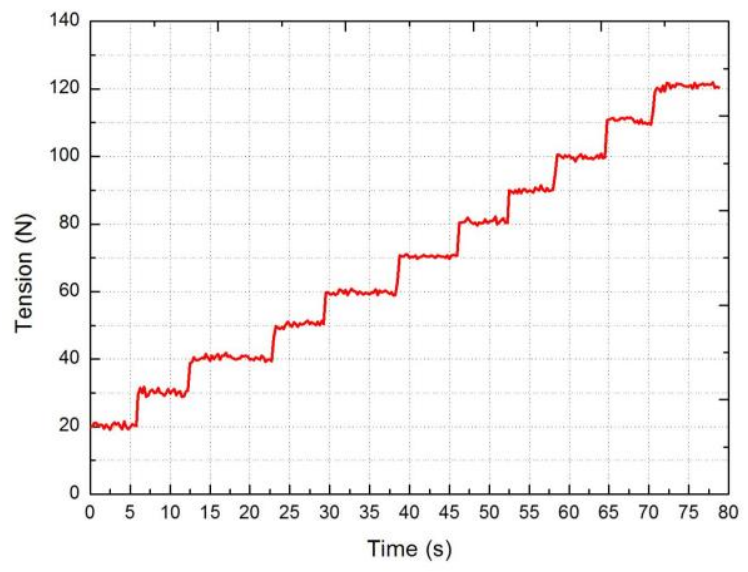

Figure 14. Tension control experiment.

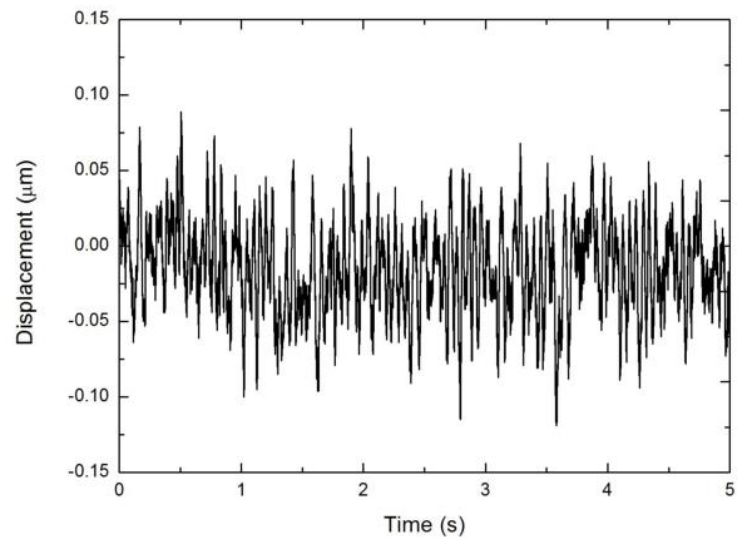

Figure 15. Environment noise of the laser sensor.

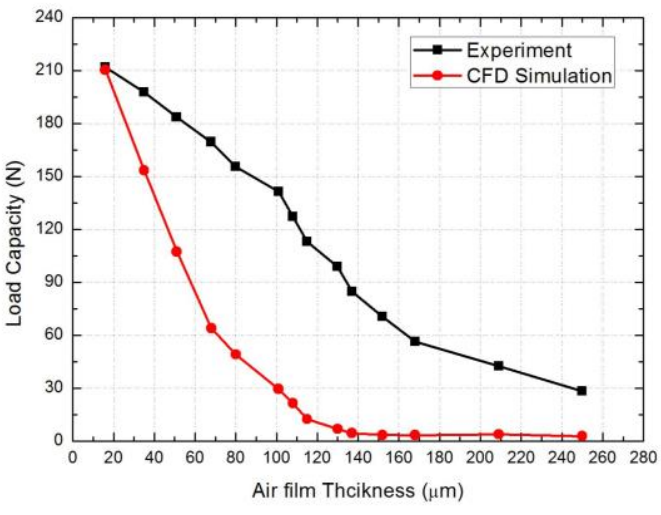

(a)

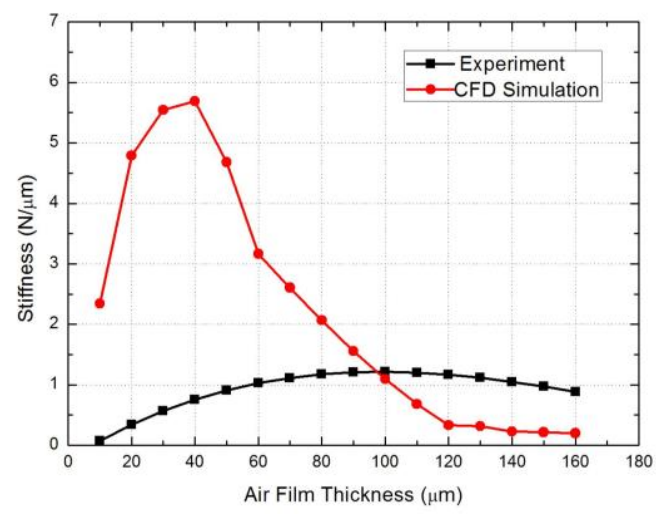

(b)

Figure 16. Comparison between the experiment and the CFD simulation: (a) load capacity comparison and (b) sti ness comparison. 
between the experimental results and the CFD simulation are shown in Fig. 16. Due to the restriction of friction between the the mechanical expansion shaft and the web reel, the tension of the web cannot be as large as the CFD condition. Therefore the web tension is set from $20 \mathrm{~N}$ to $150 \mathrm{~N}$. The load capacity is varied from $28.28 \mathrm{~N}$ to $212.13 \mathrm{~N}$ according to equation (6). Moreover, the load capacity is measured from $20 \mathrm{~m}$ of the air Im thickness. The sti ness curve is derived from the load capacity curve according to Eq. (26).

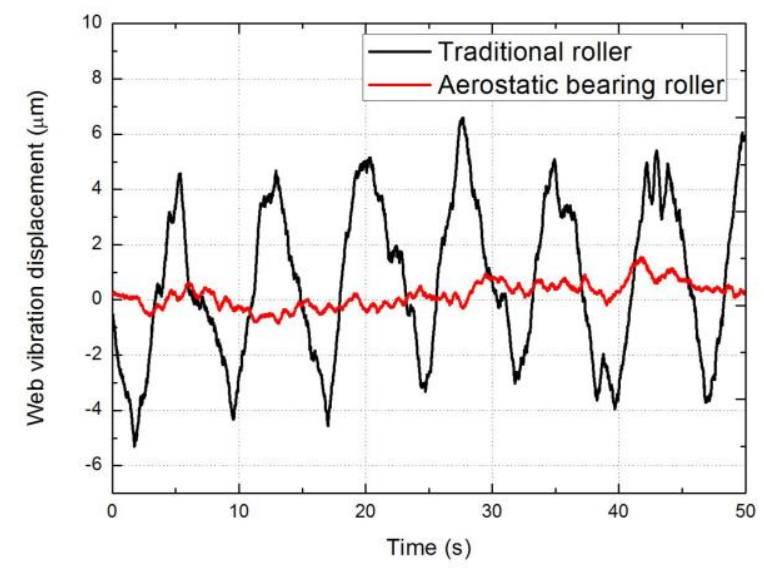

Figure 17. Web vibration comparison between the traditional roller and aerostatic bearing roller.

From the comparison chart shown in Fig 16, the following conclusions can be obtained. According to the experimental results, the CFD simulation results can re ect the trend of the load capacity and sti ness. The load capacity of the air Im decreases as the increase of the air Im thickness. The air Im sti ness has a maximum value at a particular value of the air Im thickness. Signi cant numerical di erences exist in the comparison between the CFD simulation and the experimental results. As the air Im thickness increases, the actual load capacity decreases is relatively slowly compared to the CFD simulation. The actual air Im sti ness is far below the CFD simulation value. The reasons for the di erences will be discussed later.

When the web tension is low, the thickness of the air Im would be relatively thick, resulting in a low sti ness of the air $\mathrm{Im}$. The external disturbances will interfere the position accuracy of the web. Due to the exibility of the web, the air ow will cause vibration of the web at the low tension condition. Therefore the work tension of the web should be controlled strictly. When the web tension is relatively high, the position error of the web is eliminated e ectively. The deviation displacement of the web in the vertical direction will be detected to compare with the position accuracy achieved by di erent transport methods. The laser sensor detects the position uctuations of the web at the aerostatic bearing area and the traditional rolling roller, respectively. The web tension is controlled at $150 \mathrm{~N}$, and the web velocity is at $20 \mathrm{~mm} / \mathrm{s}$. As shown in Fig. 17, the comparison chart shows the e ectiveness of the aerostatic bearing roller. 
Due to the machining and assembly errors, dynamic position error of the web on the rolling roller is detected which is about $6 \mathrm{~m}$. While the position error of web at the aerostatic bearing area is about $1 \mathrm{~m}$. Comparing to the traditional web transport method, a much better dynamic performance is obtained with the proposed aerostatic bearing method.

\subsection{Discussion}

The deviation of experimental results from the CFD simulation results arises from complex reasons as follows.

The exible web is regarded as a rigid body in the CFD boundary condition setting. In the experiment situation, when the web tension is high enough, the web can be regard as a rigid body. While at a low tension condition, the web cannot maintain the uniform plate structure because of the air Im stress concentration caused by the restrictor array.

The pressure distribution would be uneven when the air Im thickness becomes thicker, resulting in non-uniform supporting forces. From the observation of the experiments, the web would appear severe vibration at low tension. To obtain stable aerostatic bearing performance, the tension should be precisely controlled.

During the experimental process, the web is constantly moving. In the CFD simulation condition, the web motion is ignored. This may lead to changes in the boundary conditions.

Maintaining a stable aerostatic bearing status of the exible web needs strict conditions. Improper experimental parameter settings will lead to non-ideal experimental phenomena. For the proposed aerostatic bearing system, the tension should be set at least higher than $120 \mathrm{~N}$ to obtain high rigidity of the exible web. When the web is transported into the aerostatic bearing area, the cross direction error should be eliminated to guarantee the symmetry boundary condition of the ow eld. The web guide module to control the web position in the cross direction need to be introduced in the future work.

Although there is some deviation between the CFD simulation results and the experimental results, but the CFD simulation is still able to re ect the relationship between the load capacity, sti ness and the air Im thickness, which can provide theoretical support for the design of the aerostatic bearing system.

\section{Conclusion}

The study of the roll-to-roll printed electronics has raised a tough task to design precision transport equipment to guarantee the position accuracy of the web. To this end, a novel aerostatic bearing system is pesented in this paper. Design, analysis, and characterization of the aerostatic bearing system are proposed. The core part of the R2R 
system is a pair of aerostatic bearing devices with arrayed restrictors. The aerostatic bearing device can generate a layer of air $\mathrm{Im}$ between the web and the roller to eliminate the adverse impact of the traditional roller with both support and transport uses. The conception design of the device is presented and the theoretical model of the air ow eld are established. CFD numerical simulations are developed to evaluate and optimize the property of the device. Finally, a roll-to-roll prototype is built to experimentally investigate the performance of the aerostatic bearing roller. Experimental results have proved the feasibility of the proposed aerostatic bearing method. By adopting the aerostatic bearing roller, the position accuracy in the vertical direction of the web can be achieved to $1 \mathrm{~m}$, which is signi cantly better than the traditional method.

Precise tension control and cross direction error compensation are necessary for further improving the performance of the aerostatic bearing system. In the future work, an active tension adjuster and a web guide module will be developed to enhance the tension control precision and the web position accuracy. In order to further investigate the aerostatic bearing method, di erent kinds of air bearing, such as the porous bearing will be investigated to fabricate the air bearing roller. Speci $c$ air pressure sensors will be mounted on the aerostatic bearing device to detect the air pressure in di erent position of the ow eld. Moreover, a complete set of roll-to-roll inkjet printing system will be built to conduct the multi-layer printing experiment.

\section{Acknowledgement}

This work is nancially sponsored by the National Nature-Science Foundation of China with Grants 51475017 . This support is gratefully acknowledged.

\section{References}

[1] Kantola V, Kulovesi J, Lahti L et al. 2009 Bit Bang 63

[2] Perelaer J, Smith P J, Mager D, Soltman D, Volkman S K, Subramanian V, Korvink J G and Schubert U S 2010 Journal of Materials Chemistry 20 8446\{8453

[3] Allen M, Lee C, Ahn B, Kololuoma T, Shin K and Ko S 2011 Microelectronic engineering 88 $3293\{3299$

[4] Angelo P D 2013 Inkjet-printed light-emitting devices: applying inkjet microfabrication to multilayer electronics Ph.D. thesis University of Toronto

[5] Yin Z, Huang Y, Bu N, Wang X and Xiong Y 2010 Chinese Science Bulletin $553383\{3407$

[6] $\mathrm{H} \cdot a m \cdot a l \cdot a i n e n ~ H$ et al. 2012

[7] Genina N, Fors D, Vakili H, Ihalainen P, Pohjala L, Ehlers H, Kassamakov I, Haeggstr•om E, Vuorela P, Peltonen J et al. 2012 European Journal of Pharmaceutical Sciences $47615\{623$

[8] Zhang H, Poliks M D and Sammakia B 2010 Journal of display technology $6571\{578$

[9] Krebs F C 2009 Solar energy materials and solar cells $93394\{412$

[10] Kopola H, Hurme E, Kuusisto J M, Smolander M, Tuomikoski M, Kololuoma T, Hast J, K•ans•akoski M, Alastalo A, Kemppainen A et al. 2007 VTT Report

[11] Harrop P 2012 IDTechEx Report

[12] Dwivedula R V, Zhu Y and Pagilla P R 2006 Control Engineering Practice 14 409\{423

[13] Pagilla P R, Dwivedula R V, Zhu Y and Perera L P 2003 Journal of dynamic systems, measurement, and control $125361\{371$ 
[14] Zubair M, Ponniah G, Yang Y J and Choi K H 2014 Chinese Journal of Mechanical Engineering $27229\{239$

[15] Bollstrom R et al. 2012 Papercon New Orleans

[16] Kang H, Lee C and Shin K 2010 Journal of Process Control 20 643\{652

[17] Kang H, Lee $\mathrm{C}$ and Shin K 2011 IFAC Proceedings Volumes $446763\{6770$

[18] Kim C H, Jo J and Lee S H 2012 Review of scienti c instruments 83065001

[19] Kim C H, You H I and Jo J 2013 Japanese Journal of Applied Physics 52 05DB08

[20] Hao G and Yu J 2016 Mechanism and Machine Theory 102 179\{195

[21] Yang S, Chen W, Liu J and Chen W 2017 Journal of Micromechanics and Microengineering

[22] Baldesi P 2009 Design and development of high precision ve-axis positioning system for roll-toroll multi-layer microcontact printing Ph.D. thesis Massachusetts Institute of Technology

[23] Zhu Y 2009 Design and manufacturing of high precision roll-to-roll multilayer printing machine\{ machine upgrade Ph.D. thesis Massachusetts Institute of Technology

[24] Zhou X, Xu H, Cheng J, Zhao N and Chen S C 2015 Scienti c reports 5

[25] Zhou X, Wang D, Wang J and Chen S C 2016 Precision Engineering 45 332\{341

[26] Devitt A J 2012 Method and apparatus for in-line processing and immediately sequential or simultaneous processing of at and exible substrates through viscous shear in thin cross section gaps for the manufacture of micro-electronic circuits or displays uS Patent $8,123,868$

[27] Li Y and Ding H 2007 Tribology international $401120\{1126$

[28] Renn J C and Hsiao C H 2004 Tribology International 37 309\{315

[29] Powell J W 1970

[30] Liu D, Liu Y and Chen S 1990 Harbin Institute of Technology Press, Harbin, China (in Chinese)

[31] Constantinescu V N 1969 AMERICAN SOC OF MECHANICAL ENG., NEW YORK. 1969, 621 $P$

[32] Jeong T G, Seo Y H, Kim S, Song J, Ko S L, Gwak K W and Kim C W 2014 International journal of precision engineering and manufacturing $151303\{1310$

[33] Fan K C, Ho C C and Mou J I 2002 Journal of Micromechanics and Microengineering 12636 